\title{
QUEEN'S
UNIVERSITY
BELFAST
}

\section{Effect of high temperature, biaxial stretching on the thermal and mechanical properties of HDPE/MWCNT sheet}

Linton, D., Harkin-Jones, E., \& Xiang, D. (2014). Effect of high temperature, biaxial stretching on the thermal and mechanical properties of HDPE/MWCNT sheet. AIP CONFERENCE PROCEEDINGS, 070007.

http://dx.doi.org/10.1063/1.4918442

Published in:

AIP CONFERENCE PROCEEDINGS

Document Version:

Publisher's PDF, also known as Version of record

Queen's University Belfast - Research Portal:

Link to publication record in Queen's University Belfast Research Portal

Publisher rights

(C) 2015 AIP Publishing

\section{General rights}

Copyright for the publications made accessible via the Queen's University Belfast Research Portal is retained by the author(s) and / or other copyright owners and it is a condition of accessing these publications that users recognise and abide by the legal requirements associated with these rights.

Take down policy

The Research Portal is Queen's institutional repository that provides access to Queen's research output. Every effort has been made to ensure that content in the Research Portal does not infringe any person's rights, or applicable UK laws. If you discover content in the Research Portal that you believe breaches copyright or violates any law, please contact openaccess@qub.ac.uk. 


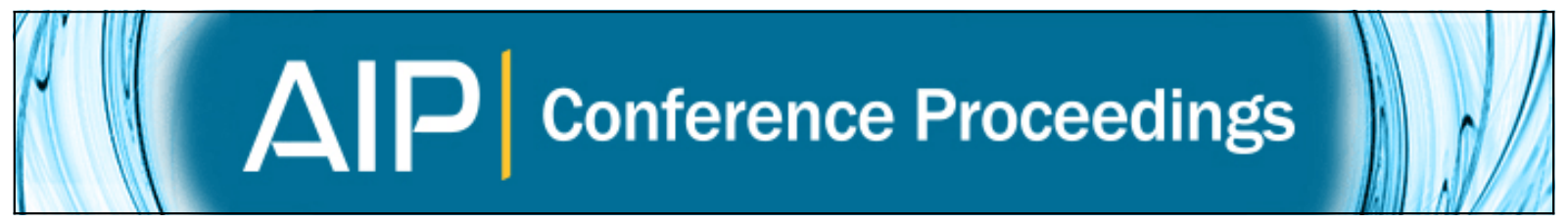

Effect of high temperature, biaxial stretching on the thermal and mechanical properties of HDPE/MWCNT sheet

Dong Xiang, Eileen Harkin-Jones, and David Linton

Citation: AIP Conference Proceedings 1664, 070007 (2015); doi: 10.1063/1.4918442

View online: http://dx.doi.org/10.1063/1.4918442

View Table of Contents: http://scitation.aip.org/content/aip/proceeding/aipcp/1664?ver=pdfcov

Published by the AIP Publishing

\section{Articles you may be interested in}

Enhanced mechanical and thermal properties of CNT/HDPE nanocomposite using MMT as secondary filler AIP Conf. Proc. 1599, 206 (2014); 10.1063/1.4876814

HDPE/MWCNT composite as microwave absorber

AIP Conf. Proc. 1593, 282 (2014); 10.1063/1.4873782

Mechanic and electromechanic effects in biaxially stretched liquid crystal elastomers

Appl. Phys. Lett. 102, 052901 (2013); 10.1063/1.4790154

Non-isothermal Crystallization Behaviors of HDPE/MWCNT Nanocomposites

AIP Conf. Proc. 1353, 761 (2011); 10.1063/1.3589607

Effect of Biaxial Stretching at Temperatures and Strain Histories Comparable to Injection Stretch Blow Moulding on Tensile Modulus for Polyethylene Terephthalate (PET)

AIP Conf. Proc. 907, 835 (2007); 10.1063/1.2729617 


\title{
Effect of high temperature, biaxial stretching on the thermal and mechanical properties of HDPE/MWCNT sheet
}

\author{
Dong Xiang ${ }^{\mathrm{a}}$, Eileen Harkin-Jones ${ }^{\mathrm{a}}$, David Linton ${ }^{\mathrm{b}}$ \\ ${ }^{a}$ School of Mechanical and Aerospace Engineering, Queen's University Belfast, BT9 5AH, UK \\ ${ }^{b}$ School of Electronics, Electrical Engineering and Computer Science, Queen's University Belfast, BT9 5AH, UK
}

\begin{abstract}
High density polyethylene (HDPE)/multi-walled carbon nanotube (MWCNT) composites containing 4 wt\% MWCNTs were prepared by melt mixing followed by compression moulding into sheet. Compression moulded sheets were heated to just below the melting temperature and biaxially stretched at ratios (SRs) of 2, 2.5 and 3.0. The effect of stretching on the thermal and mechanical properties of the sheet was studied by differential scanning calorimetry (DSC) and tensile testing. DSC results show that the crystallinity of all the stretched samples increases by approximately $13 \%$ due to strain induced crystallization. The melting temperature of the biaxially stretched samples increases only slightly while crystallization temperature is not affected. Tensile test results indicate that at a SR of 2.5 the elastic modulus of the stretched composites increases by $17.6 \%$ relative to the virgin HDPE, but the breaking strength decreases by $33 \%$. While the elastic modulus and breaking strength of the HDPE/MWCNT samples continue to increase as SR increases they drop off after a SR of 2.5 for the virgin HDPE. This is probably due to the constraining influence of the nanotubes preventing the relaxation of polymer chains caused by adiabatic heating at high SRs. The addition of MWCNTs results in significant strain hardening during deformation. While this will lead to increased energy requirement in forming it will also result in a more stable process and the ability to produce deep draw containers with more uniform wall thickness.
\end{abstract}

Keywords: Biaxial stretching; High density polyethylene; Carbon nanotubes; Polymer composites; Processing; Manufacturing.

PACS: $81.05 . \mathrm{Qk}$

\section{INTRODUCTION}

Carbon nanotube (CNT) reinforced polymers are growing rapidly in demand in many application areas including electrostatic dissipation, electronic conductivity, electromagnetic interference shielding etc. [1,2]. The processing route to produce a product can have an important influence on the structure $[3,4]$ and final properties $[5,6]$ and, changes in material thermal and rheological properties due to the addition of nanoparticles can also significantly alter processability [7,8]. Many polymer products are formed via free surface moulding processes such as stretch blow moulding and thermoforming. In these processes the deformation is essential biaxial elongation so it is important to assess new materials under this deformation regime prior to industrial deployment. The effect of uniaxial stretching on the structure and properties of polymer/CNT composites has been extensively investigated $[9,10,11]$. However, few investigations on the effect of biaxial stretching on polymer/CNT composites have been carried out $[1,12]$. In this present study, the high temperature, biaxial stretching of a high density polyethylene (HDPE) based MWCNT nanocomposite is conducted. The influence of MWCNT inclusion on processability is examined and the effect of biaxial deformation on the thermal and mechanical properties of HDPE/MWCNT composites is investigated.

\section{EXPERIMENTAL}

\section{Materials}

The HDPE (HTA108) used in this study was purchased from ExxonMobil. It has a high intrinsic viscosity (MFI $=0.7 \mathrm{~g} / 10 \mathrm{~min}$ ) and a density of $0.961 \mathrm{~g} / \mathrm{cm}^{3}$. The MWCNTs $(\mathrm{NC} 7000)$, produced via catalytic chemical vapour deposition, were kindly supplied by Nanocyl SA. The purity of the MWCNTs is $90 \%$. The nanotubes have a nominal diameter of $9.5 \mathrm{~nm}$ and an average length of $1.5 \mu \mathrm{m}$ [13]. The density of the MWCNTs is $1.85 \mathrm{~g} / \mathrm{cm}^{3}$ [14]. 


\section{Sample preparation}

The HDPE pellets were ground into a powder using a Wedco 12" plant grinder. The HDPE powder was premixed with the MWCNTs using a high speed mixer (PRISM Pilot 3), at a MWCNT loading of 4 wt\%. The blends were compounded in a Dr. Collin twin screw extruder ZK 25 with a temperature profile of 175, 220, 220, $215,210,200^{\circ} \mathrm{C}$ from zones 1 to 6 . The screw speed was set at $150 \mathrm{rpm}$. The extruded strand was cooled in a water bath and then pelletized. The pellets were compression moulded in a steel mould of $1 \mathrm{~mm}$ thickness at $200^{\circ} \mathrm{C}$ for 5 min using a Dr. Collin P200P platen press machine in order to produce sheet material for biaxial stretching.

Biaxial stretching of the sheets was conducted using the Queen's biaxial stretcher [15,16]. The samples of dimension $76 \mathrm{~mm} \times 76 \mathrm{~mm} \times 1 \mathrm{~mm}$ were clamped by pneumatic grippers and then heated by hot air blowers for 4 minutes before simultaneously and equi-biaxially stretching. The samples were cooled to room temperature in ambient air at the end of stretching. The stretching parameters used in this study were as follows: stretching temperature: $131^{\circ} \mathrm{C}$, stretch ratio: $2,2.5$ and 3.0, strain rate: 4/s. Each stretching test was repeated twice, and sample codes for the stretched and compression moulded samples are shown in Table 1.

TABLE (1). Sample codes for the stretched and unstretched samples.

\begin{tabular}{lcc}
\hline Sample & Sample code & Stretch ratio \\
\hline \multirow{3}{*}{ HDPE } & HDPE-CM & 1.0 \\
& HDPE-2.0 & 2.0 \\
& HDPE-2.5 & 2.5 \\
& HDPE-3.0 & 3.0 \\
HDPE/MWCNT & CNT4-CM & 1.0 \\
$(4 \mathrm{wt} \%)$ & CNT4-2.0 & 2.0 \\
& CNT4-2.5 & 2.5 \\
& CNT4-3.0 & 3.0 \\
\hline \multicolumn{2}{l}{ "CM" in the sample codes means compression moulded. }
\end{tabular}

\section{Characterization}

Scanning electron microscopy (SEM)

The morphologies and dispersion of MWCNTs in the HDPE matrix were investigated using a JEOL 6500F scanning electron microscope. Cryo-fractured samples were prepared and gold sputtered prior to imaging.

Differential scanning calorimetry (DSC)

A Perkin-Elmer DSC model 6 was used to measure the melting and crystallization behaviour of the HDPE and HDPE/MWCNT composites under an inert nitrogen atmosphere. The samples were heated from $30^{\circ} \mathrm{C}$ to $200^{\circ} \mathrm{C}$ at a heating rate of $10^{\circ} \mathrm{C} / \mathrm{min}$, held at $200^{\circ} \mathrm{C}$ for $3 \mathrm{~min}$, followed by a cooling process from $200^{\circ} \mathrm{C}$ to $30{ }^{\circ} \mathrm{C}$ at a cooling rate of $10^{\circ} \mathrm{C} / \mathrm{min}$. Three runs were conducted for each sample. The enthalpy of fusion of $100 \% \mathrm{HDPE} \mathrm{crystal}\left(\Delta \mathrm{H}_{m}^{\circ}\right)$ was taken as $293 \mathrm{~J} / \mathrm{g}$ [17].

\section{Tensile testing}

Tensile tests were conducted using an Instron 5564 Universal Tester at room temperature (BS EN ISO 527:1996). The specimens were prepared by cutting samples from the middle of sheets. Tensile modulus was determined using a clip-on extensometer at a crosshead speed of $5 \mathrm{~mm} / \mathrm{min}$. Strength and elongation values were taken at a crosshead speed of $50 \mathrm{~mm} / \mathrm{min}$. Five samples were tested for each sheet and average values were calculated. 


\section{RESULTS AND DISCUSSION}

\section{Morphology and dispersion}

The morphology of pristine MWCNTs and the dispersion of MWCNTs in the HDPE matrix were investigated using a SEM microscope, as shown in Figure 1. Figure 1 (a) shows how individual MWCNTs tend to form clusters naturally as a result of the strong Van der Waals force. Although the shear force during melt mixing is effective in dispersing the MWCNTs in the polymer, it is not possible to disentangle all the MWCNT clusters. Therefore, both isolated and agglomerated MWCNTs in the matrix can be observed in Figure 1 (b).
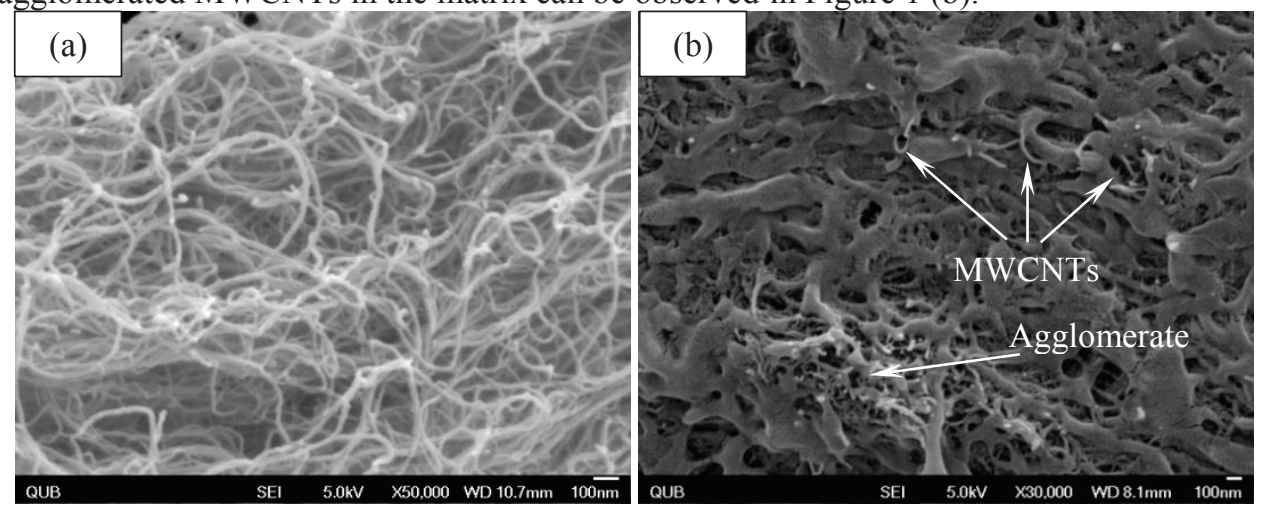

FIGURE 1. SEM micrographs: (a) morphology of pristine MWCNTs; (b) dispersion of MWCNTs in the HDPE.

\section{Effect of MWCNTs on deformation behaviour}

Figure 2 shows the biaxial stress-strain curves for the filled and unfilled HDPE sheet stretched to a stretch ratio of 3.0. A higher stretching stress and an obvious yield point can be seen with the addition of MWCNTs during deformation. This peak is not found during the biaxial stretching of iPP/CNT composites in Shen's study [12]. The yield stress of the composites containing $4 \mathrm{wt} \%$ MWCNTs increases by $218 \%$, which means the force required to deform the MWCNT filled materials will have to be substantially increased. The increase in yield stress for the filled material may be attributed to restrictions in molecular mobility of molecules due to the presence of the MWCNTs. As stretch ratio increases, the MWCNT composite exhibits strong strain hardening behavior. This is quite different to the behavior of the virgin HDPE which, as expected, shown no strain hardening. This strain hardening will contribute to a more stable deformation process and uniform sheet thickness distribution of the final stretched sheet.

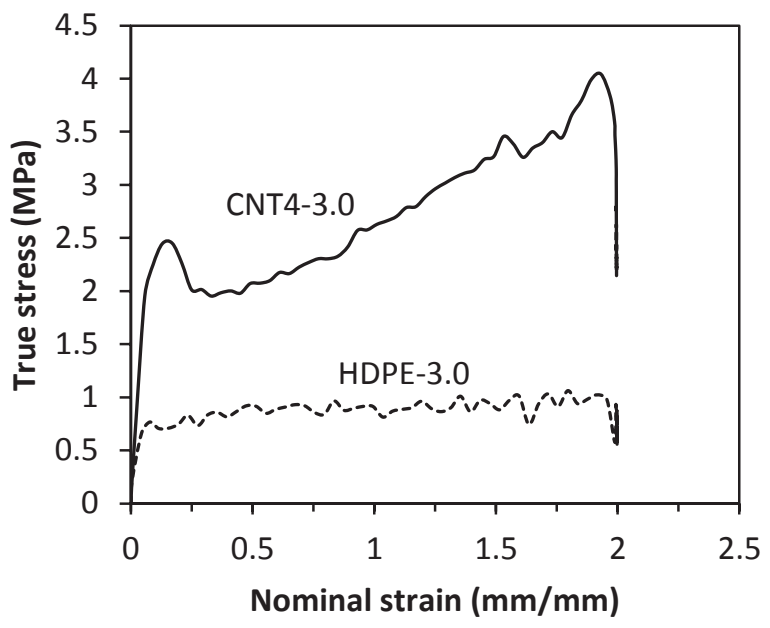

FIGURE 2. Effect of MWCNTs on the biaxial deformation behaviour of HDPE. 


\section{Effect of biaxial stretching on thermal properties}

The crystallinity, melting temperature $\left(T_{m}\right)$ and crystallization temperature $\left(T_{c}\right)$ of all samples are shown in Figure 3. It can be observed that the curves for the stretched samples exhibit evidence of recrystallization. The effect is less pronounced for the composite material. Detailed DSC results are shown in Table (2). The results show that the crystallinity of all the stretched samples increases by approximately $13 \%$ due to strain induced crystallization. The $\mathrm{T}_{\mathrm{m}}$ of the biaxially stretched samples increases only slightly. The $\mathrm{T}_{\mathrm{c}}$ of the compression moulded HDPE/MWCNT sample increases by $2^{\circ} \mathrm{C}$ with the addition of MWCNTs thanks to the nucleation effect of MWCNTs, while it is not substantially affected by biaxial stretching. This means that the composite material can be demoulded earlier than the unfilled material resulting in a somewhat reduced cycle time.
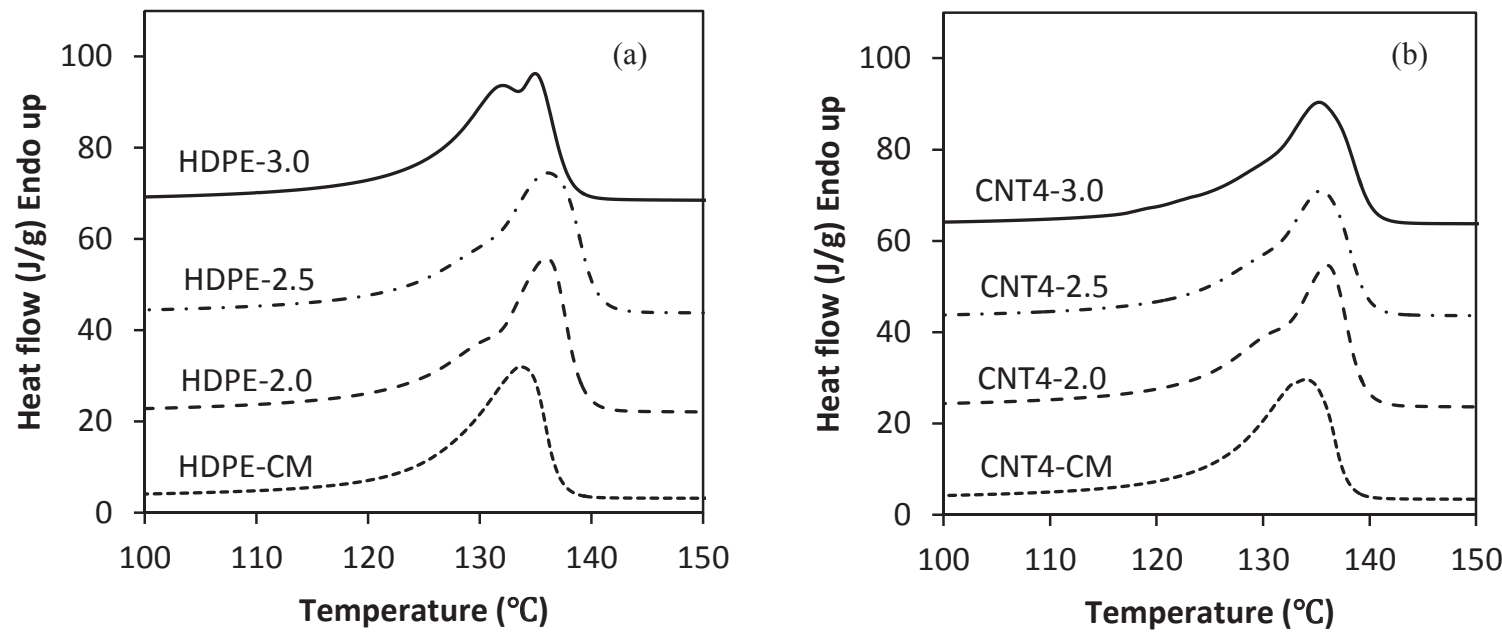

FIGURE 3. DSC heating curves for the stretched and unstretched (a) HDPE and (b) HDPE/MWCNT sheets.

TABLE (2). DSC tests for the stretched and unstretched samples.

\begin{tabular}{lccc}
\hline Sample code & Crystallinity $(\%)$ & $\mathbf{T}_{\mathbf{m}}\left({ }^{\circ} \mathrm{C}\right)$ & $\mathbf{T}_{\mathbf{c}}\left({ }^{\circ} \mathrm{C}\right)$ \\
\hline HDPE-CM & $72.8( \pm 3.1)$ & $133.9( \pm 0.2)$ & $114.0( \pm 0.2)$ \\
HDPE-2.0 & $86.6( \pm 0.6)$ & $136.4( \pm 0.3)$ & $113.1( \pm 0.3)$ \\
HDPE- 2.5 & $86.0( \pm 2.9)$ & $135.7( \pm 0.4)$ & $113.7( \pm 0.4)$ \\
HDPE-3.0 & $85.7( \pm 2.9)$ & $135.2( \pm 0.2)$ & $113.6( \pm 0.3)$ \\
CNT4-CM & $73.9( \pm 5.1)$ & $134.0( \pm 0.1)$ & $116.0( \pm 0.2)$ \\
CNT4-2.0 & $84.4( \pm 5.0)$ & $135.9( \pm 0.4)$ & $115.7( \pm 0.4)$ \\
CNT4-2.5 & $86.1( \pm 2.1)$ & $136.1( \pm 0.7)$ & $115.7( \pm 0.5)$ \\
CNT4-3.0 & $85.5( \pm 3.0)$ & $135.4( \pm 0.2)$ & $116.0( \pm 0.4)$ \\
\hline
\end{tabular}

\section{Effect of biaxial stretching on mechanical properties}

Mechanical results are shown in Figure 4. The modulus of the compression moulded HDPE/MWCNT sheet increase by $112 \%$ compared with the pure HDPE while the breaking strength decreases by $40 \%$. At a SR of 2.5 , the elastic modulus of the stretched composites increases by $17.6 \%$ relative to the virgin HDPE and the breaking strength decreases by $33 \%$. While the elastic modulus and breaking strength of the HDPE/MWCNT samples continues to increase as stretch ratio increases they drop off after a SR of 2.5 for the virgin HDPE. The deterioration in the modulus and breaking strength of the biaxial stretched HDPE sheets at a stretch ratio of 3 may be attributed to molecular relaxation caused by adiabatic heating at high stretch ratios. The presence of nanotubes is likely to prevent this relaxation at high SRs resulting in a consistent improvement in mechanical properties. 

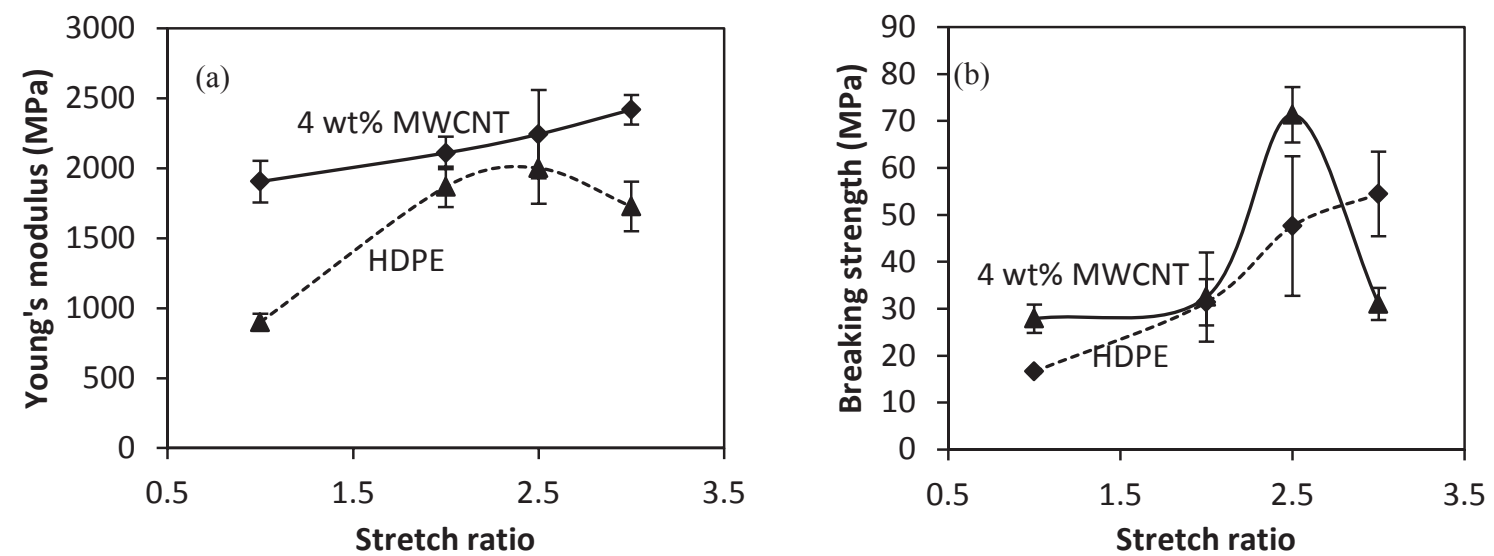

FIGURE 4. Variation in (a) Young's modulus and (b) breaking strength of HDPE and MWCNT/HDPE samples as a function of stretch ratio.

\section{CONCLUSIONS}

In this paper, high density polyethylene (HDPE)/multi-walled carbon nanotube (MWCNT) composites containing $4 \mathrm{wt} \%$ MWCNTs were prepared by melt mixing followed by compression moulding into sheet. Isolated and agglomerated MWCNTs in the matrix were observed by SEM. A significant strain hardening during deformation was observed with the addition of MWCNTs. DSC results show an evident increase $(\sim 13 \%)$ in crystallinity for all the stretched samples due to strain induced crystallization. The melting temperature of the biaxially stretched samples increases only slightly while crystallization temperature is not affected. The modulus of HDPE/MWCNT sheet increases by $112 \%$ but the breaking strength decreases by $40 \%$ compared with the pure HDPE sheet. The modulus and breaking strength of biaxially stretched composites can be improved consistently with increasing SRs, while they drop off after a SR of 2.5 for the virgin HDPE.

\section{ACKNOWLEDGMENTS}

The authors would like to thank CSC and QUB Overseas Scholarship for the financial support provided.

\section{REFERENCES}

1. J. Shen, M. F. Champagne, Z. Yang, Q. Yu, R. Gendron, and S. Guo, Compos. Part A-Appl. S. 43, 1448-1453 (2012).

2. P. Verge, S. Benali, L. Bonnaud, A. Minoia, M. Mainil, R. Lazzaroni, and P. Dubois, Eur. Polym. J. 48, 677-683 (2012).

3. B. Xu, J. Leisen, H. Beckham, R. Abu-zurayk, E. Harkin-Jones, and T. McNally, Macromolecules 42, 8959-8968 (2009).

4. S. Xie, E. Harkin-Jones, Y. Shen, P. Hornsby, M. McAfee, T. McNally, R. Patel, H. Benkreira, and P. Coates, Mater. Lett. 64, 185-188 (2010).

5. R. Abu-Zurayk, and E. Harkin-Jones, Polym. Eng. Sci. 52, 2360-2368 (2012).

6. R. Abu-Zurayk, E. Harkin-Jones, T. McNally, G. Menary, P. Martin, C. Armstrong, and M. McAfee, Compos. Sci. Technol. 70, 1353-1359 (2010).

7. Y. Shen, E. Harkin-Jones, P. Hornsby, T. McNally, and R. Abu-Zurayk, Compos. Sci. Technol. 71, 758-764 (2011).

8. K. Soon, E. Harkin-Jones, R. Rajeev, G. Menary, T. McNally, P. Martin, and C. Armstrong, Polymer. Int. 58, $1134-1141$ (2009).

9. M. Park, H. Kim, and J. Youngblood, Nanotechnology 19, 055705 (2008).

10. Q. Wang, J. Dai, W. Li, Z. Wei, and J. Jiang, Compos. Sci. Technol. 68, 1644-1648 (2008).

11. F. Du, J. Fischer, and K. Winey, Phys. Rev. B 72, 121404 (2005).

12. J. Shen, M.F. Champagne, R. Gendron, and S. Guo, Eur. Polym. J. 48, 930-939 (2012).

13. T. Villmow, S. Pegel, P. Pötschke, and U. Wagenknecht, Compos. Sci. Technol. 68, 777-789 (2008).

14. M. Morcom, K. Atkinson, and G. Simon, Polymer 51, 3540-3550 (2010).

15. P. Martin, C. Tan, K. Tshai, R. McCool, G. Menary, C. Armstrong, and E. Harkin-Jones, Plast. Rubber. Compos. 34, 276$282(2005)$.

16. G. Menary, C. Tan, E. Harkin-Jones, C. Armstrong, and P. Martin, Polym. Eng. Sci. 52, 671-688 (2012).

17. B. Wunderlich, Macromolecular physics, volume 3-crystal melting. New york: Academic Press, 1980. 